\title{
Influence of Peirce's Semiotics on the Signification of Literary Discourse
}

\author{
Mohammad B. Aghaei \\ Department of English language, Islamic Azad University, Tabriz Branch, Tabriz, Iran \\ *Corresponding Author: aghaeimb@yahoo.com
}

Copyright $@ 2015$ Horizon Research Publishing All rights reserved.

\begin{abstract}
Semiotics principally investigates and explores the production and function of signs and sign systems as well as the methods of their signification. It is mainly concerned with how a sign signifies and what precedes it at deeper level to result in the manifestation of its meaning. For this purpose, it offers a set of unified principles that underlie the construction, signification and communication of any sign system. The literary text as a sign system serves as an artfully constructed fictional discourse that can be signified as the same way of the signification of other sign systems. This article explains the effects of Charles Sanders Peirce's theory of signs on the development of a clear methodological principle for the narrative studies, particularly for the signification of literary discourse. So it tries to give a new direction to the signification of literary discourse on the basis of the Peirce's theory of signs and cognitive theories. It mainly provides a semiotic method for the signification of literary discourse.
\end{abstract}

Keywords Signification, Assimilation, Accommodation, Lingual Aesthetics, Fictionality, Poeticity, Inquistoriality, Contemplation, Significative Value, Semiosis, Peirce's Trichtomies, Icon, Index, Qualisign, Sinsign, Legisign, Dicent, Argument and Cognitive Frames

\section{Introduction}

During the last two decades, the literary semioticians have made significant efforts to present an unambiguous and comprehensive approach to explain and account for the process of signification involved in different kinds of literary discourse. They have tried to offer frameworks which show an increasing tendency towards an integration of the earlier structuralist paradigms, the contemporary postulates of cognitive sciences and the Peircian semiotic formulations. The application of these fields for the study of literary texts brings about the development of a new phase of literary semiotics that is different from the literary semiotics of the 1950s that mostly had a structural orientation toward the study of narrative. What is more highlighted in this newly developed phase is that the literary semiotics emphasizes on three main points; first, the literary text is a complex micro-system of signs built of iconic, indexical and symbolic signs (according to Peirce's theory of signs). Second, the literary text is "a mental activity..., [it] is a product of its author's mind, and it has its life in the minds of viewers or readers. Hence, a psychological and/or a phenomenological dimension, as well as approaches from cognitive studies ...should be included in the study of literature as a specific form or representation" (Johansen 2007b: 7). Third, the literary text should be studied as a culturally contextualized discourse that also interacts with other public discourses of society.

\section{Peirce's Semiotics and Literary Theory}

It was only recently that the literary critics realized the importance of Charles Sanders Peirce's semiotics in the development of "various orders of relations between semiotics and literature" (Santaella 2007: 63). The typology of signs suggests that the signification issue, as elaborated by Peirce, serves as a paradigm for grasping "the semiotic movements taking place at the heart of the literary works" (Fisette 2007: 77). The updating of Peirce's semiotics proliferates the field of literary studies beyond those aspects that have been earlier considered as the bases for the formation of literary theories.

In Peirce's semiotics, as a phenomenological enterprise, all signs are classified into three groups; the first group includes 'qualisign, sinsign and legisign', the second group includes 'icon, index and symbol' and the third group includes 'rheme, dicent and delome or argument'. These nine types of signs are correlated with their objects or concepts through three 'modalities of being' such as firstness, secondness and thirdness. These modalities give meaning to all phenomena and to all objects of thought. In fact, all phenomena are regarded as manifestation of these modalities. The following scheme presented by Noth (1990) clearly indicates how these modalities can signify Peirce's trichotomies of signs. 


\begin{tabular}{|c|c|c|c|}
\hline $\begin{array}{c}\text { Trichotomy } \\
\text { Category }\end{array}$ & $\begin{array}{c}\text { I } \\
\text { of the } \\
\text { representamen }\end{array}$ & $\begin{array}{c}\text { II } \\
\text { of relation } \\
\text { to object }\end{array}$ & $\begin{array}{c}\text { III } \\
\text { of relation to } \\
\text { interpretant }\end{array}$ \\
\hline Firstness & Qualisign & Icon & Rheme \\
\hline Secondness & Sinsign & Index & Dicent \\
\hline Thirdness & Legisign & Symbol & Argument \\
\hline
\end{tabular}

Here, we don't intend to explain all the signs and how they combine and constitute other signs. Our aim here is to show how Peirce's semiotics can offer important methodological tools to study literary texts. We shall only concentrate on the modalities that constitute the signification process of literary text.

Firstness refers to the mode of mere being without reference to anything else. Examples are unreflected feeling, a mere sensation of color and form; possibility or quality. Peirce (1931) describes firstness as the 'mode of being of that' without reference to any subject or object. For instance, the mode of being of a 'redness' before anything in the universe was yet red. Secondness involves the relation of first to a second. It may take place by action, reaction, causality, reality, actuality, or factuality of things that exist in our senses as well as themselves producing physical effects. For instance, the stone that we drop falls to the ground, the weathervane turns to point in the direction of the wind, and one feels pain because of a toothache. Thirdness may be represented by thought, continuity, order, unity, or generality. Thirdness refers to itself by comparing one thing to another, establishing in that comparison a synthetic 'law' in the sense of a predictive concept. For instance, the law of gravity allows us to predict that each time we drop a stone, it will fall to the ground and when 'red' as a color stands for violence, patriotism or danger. As a whole, thirdness brings a second in relation to a third. It is a category of mediation, habit, thought, continuity, synthesis, communication (semiosis) and representation of signs. In fact, it makes possible the interpretation of social communication as well as any sign system. Thirdnes thus involves a logical and intellectual activity that takes place in the interpreter's cognition.

Peirce's semiotics significantly contributes to the formation of a modern cognitive approach that can also be used to explain the process of literary signification. If Peirce's classification of signs is taken as a basis for the literary studies, the literary text has an iconic nature that can be explained in terms of the modalities since the literary text "manipulates the iconic potential of language and embodies meaning in the words themselves. This manipulation transfigures conventionality into motivated senses that emerge at the surface of the words. It is under the power of analogies, at the core of iconicity, that literary language, in its quintessence which is poetry, comes closer to...reality" (Santaella 2007: 62). Iconicity is an important feature of all literary texts or other sign systems, and emphasizes on the establishment of correlation between 'form' and 'meaning'. It may happen at the syntactical, phonological and morphological levels since "an icon is a sign which refers to the Object that it denotes merely by virtue of characters of its own, and which it possesses, just as the same, whether any such Object actually exists or not" (Peirce 1931: 2.247).

Monica Gonzalez-Marquez has taken a similar view that "the relationship between linguistic forms and their meaning is often iconic. An iconic relationship between a symbol and its referent is one in which the symbol shares some structures with the thing that it represents. While linguists have traditionally assumed the relationship between the words and their referents is arbitrary and established by convention, cognitive linguists point a much higher degree of iconicity in language" (Gonzalez-Marquez 2006: 415). The notion of iconicity mainly refers to a natural resemblance or analogy between 'signifier' and 'signified.' According to a set of considerable linguistic researches that have been done in the twentieth century, iconicity operates at every level of language, from its smallest elements like phonemes and morphemes, to words, phrases, sentences and even paragraphs. Recent literary studies have also confirmed that iconicity is also pervasive in the literary text, from its prosody, rhyme, linearity, stanza, mood, imagery to its textual and narrative structure. It is important to realize that the perception of iconicity of literary texts has a semantic basis. The perception and interpretation of the iconic features of literary texts always depends on the hermeneutic ability of the interpreter. Gonzalez-Marquez believes that the works on iconicity have been rejuvenated by the cognitive linguistic perspectives. In addition to studying iconicity as an instance of conceptual mapping, researchers have begun to examine its relation to other cognitive processes such as metaphor (Gonzalez-Marquez 2006: 179). Thus, the notion of iconicity comprises metaphors because, according to Peirce's view, a metaphor brings out "the representative character of a sign by representing a parallelism in something else: for instance, a lion may represent a (brave) man" (Langendonck 2007: 398). It implies that the metaphorical iconicity is primarily based on "an iconic ground which is not shared between the representamen of the sign and the object referred to, but between the sign's object and new object with which the sign is connected" (Ludovic 2008: 81). The notion of iconicity can also be applicable for the signification of other figurative aspects of the literary text.

\section{Peirce's Semiosis and the Aesthetic Work}

Peirce defines the sign in terms of a triadic process, called semiosis, that consists of a first, called representamen, which stands in a triadic relation to a second, called its object, "as capable of determining a third, called its interpretant" (Peirce 1931: 2.74). If Peirce's sign-process is taken as a semiotic framework for explaining the signification of a text, it can be said that the texts, like all language signs, "consist in the first place of legisign, since they are signs that belong to the repertoire of a general code. This is the most general characterization of textuality. However, in every specific act of text production and text reception, the representamen is a 
sinsign, being unique in time, space, and communicative situation. More specific features which make a text a sinsign are its characteristics of style, textual originality, and creativity" (cited in Noth 1990: 46). But a text appears as a qualisign whenever its phonetic-graphic quality, its visual or sound effects are considered. For instance, a poetic text is a qualisign since it refers to an object because of some trait it possesses. In Peirce's own aesthetics, art and literature are essentially associated with the category of firstness. In other words, the essence of aesthetic creation has to do with "qualities of feeling" (Peirce 1931: 1.43). Peirce indeed found that "there are three general classes of signifícate effects proper to the sign (5.283). The first is the feeling produced by it; this calls the 'emotional interpretant.' Through the mediation of the emotional interpretant a further effect is produced, which Peirce calls the 'energetic interpretant.' The third signifícate effect produced by a sign is the 'logical' or 'teleological' interpretant; this is interpretant that Peirce calls the meaning or significance, of the conceptional complex or sign" (cited in Tejera 1995: 42-3). From the point of view of the textual object, the text can have multiple functions; that is, a text can take the form of iconic, indexical or symbolic sign, or their combination. Symbolic sign refers to the object that it denotes by virtue of an association of general ideas which cause it to be interpreted as referring to that object. Symbolic sign is mainly based on thirdness. Indexical sign basically refers to the object that it denotes by virtue of being really affected by that object. Indexical sign has a conative or appellative nature such as commanding and instructional statements. Dramatic texts, for instance, also predominantly function as indexical signs. Indexicality is furthermore characteristic of realism in literary text because indexical signs refer to persons, objects, and events in a more or less precise temporal, spatial, and social discourse of the text. Textual iconicity can have the form of an image, a diagram, or a metaphor. From the point of view of the textual interpretant, the text can appear as 'rheme, dicent or argument (delome). ${ }^{1}$ The text is a rheme "when it is incomplete, when it has a predominantly expressive function, or when its structure is open to many interpretations" (op. ct.: 47). Johansen claims that the rheme, as the sign of possibility, and not of factuality, is characteristic of literary and poetic textuality. The essence of fiction and imagination is of a rhematic nature (Johansen 1986). The fictional texts have the character of a dicent, since they are informational. The texts can thus have different interpretants, depending on their function and the interpreters who interacts with the texts. Therefore, in the interaction of the reader with a literary work, he is actually engaged in a qualitative complex system that "is potentially a whole, potentially intelligible, and promissory of some gain in pleasure or knowledge. To call a work 'potentially whole' is, in Peircean terms to say that it is rhematic (a First); to call

\footnotetext{
${ }^{1}$. An argument is a sign which is understood to represent its object in its character as a sign. A rheme is a sign which is understood to represent its object in its characters merely. Ddicent is a sign which is understood to represent its object in respect to actual existence (Peirce 1931: 2.252).
}

it 'intelligible' is to say that it is symbolic (or argumental), a Third - while taking note of the fact that it is both qualitative and complex. That a work is pleasing makes it indexical, connects it existentially to its reader, as does the fact that it informs, especially when we remember (with Aristotle) that knowledge must, among other things, affect its beneficiary if it is to qualify as knowledge. And the mode of being of what is existential is Secondness" (Tejera 1995: 40-1). Semiologically speaking, the literary work can be thus considered as an indexical symbolic argument because it conveys a message to the reader. It indeed has a hypoiconic relationship with its subject-matter or object and presupposes any number of conventions. Therefore, the significance of the literary text is mainly attainable by the reader who actually engages his experience and literary competence in the process of signification.

Therefore, in an aesthetically grounded work that is globally taken as a sign, the object of the work is its subject-matter. An aesthetic work is basically "grounded in the material to which the artist must give shape on the basis of his abstractive observation of it. Peirce's wording lets us see the interpretant is not just an effect upon the reader's response-system, but that it is mediated, brought about, by the literary artist's thematic subject-matter, his constructed sign and the shape it has received" (Tejera 1995: 33-4). The reader responds to the narrative, dramatic and poetic styles of structuring of the text which are significant factors in giving literariness or an aesthetic ground to the work. The reader's main goal is to create a conceptual image of the subject matter, i.e. object, of the whole discourse. In order to do so, he mostly tries to analyze the aesthetic dimensions of the text because a proper interpretation of a literary text depends on the interpretation of its aesthetic aspects. As a sign "addresses somebody, that is, creates in the mind of that person an equivalent sign, or perhaps a more developed sign" (Peirce 1931: 2.228), the reader thus mentally creates a comprehensive image of the story, even sometimes more comprehensive than the image that the literary discourse itself actually portrays about the story.

The qualities or aesthetic aspects of the literary work depend on the creative skills of the author in the manipulation of the textual material for reshaping and representing his thematic raw materials. The author applies different literary devices for aesthetically organizing the text in order to convey his intended message to the reader in the discourse that is most often enriched with the associated meanings. Therefore, the aesthetically grounded text intrinsically has "a self-focusing quality, so that its structural arrangement becomes one of the contents that it conveys....It represents the proposal of a new coding possibility" (Eco 1976: 269-70). In fact, an aesthetic text is dexterously and intentionally articulated in order to transform "its denotation into new connotations" (ibid.: 274). Therefore, an aesthetic text has a double-functional nature; that is, it has both denotative and connotative meaning. In simple words, it conveys an unknown beyond the known. Consequently, it 
serves as "means of apprehending the Invisible, the Ineffable, the Irrational and, in general, abstract psychic experience through the concrete experience of the senses" (Guiraud 1975: 68). It compels the reader to consider the usual codes and their possibility of appearing in various implications. Whereas, in the creation of a literary work, the author's intention is to give the thematic raw materials an aesthetic ground by applying various literary devices, the reader thus constantly puts the aesthetic aspects of the text under his judgment and interpretation by comparing them with his cognitive frames. It indicates that the reader's expressed interpretation of the literary work appeals to his personal experience and judgment on the author's thematic material and the way he has constructed the work as an abstraction from his thematic raw materials.

\section{Effects of Cognition on Signification}

Any type of meaningful communication is a result of the cognitive activities on the part of the participants, i.e. the addresser and addressee. Human beings have been intrinsically equipped with the cognitive faculty to receive, process and send different types of messages, just as they have been physiologically endowed to see, hear, smell, taste and touch. Their cognitive faculty creates a multi-dimensional cognitive structure that makes it possible for them to communicate and make meaningful relationships with their environment. They thus effortlessly construct the concept of signs, describe a situation and use their imaginative skills in the forms of verbal or non-verbal narratives including drawings, films, or novels, etc. All these narratives, whether fictional or factual, are constructed by their cognitive activities. Hence the signification of these narratives requires the cognitive participation of the interpreter. Analogously, for the signification of the literary text, the reader has to activate his cognitive faculty and literary competence in order to portray a mental image of the whole story world that it may cause the reader to go "beyond the text to explain and predict aspects of the story" (Gerrig and Allbriton 1990: 380). The reader's cognitive participation actually helps him to bring out the similar or shared features between the story world and the real world. In order to do so, he first has to find a coherent interrelationship between various narrative elements such as characters, settings and events. Then he has to form relevant cognitive frames that are similar to the story world of the narrative. The cognitive frames have been continuously formed during one's life and stored in the mind in the form of 'schema', 'script' and 'scenario'. These frames actually provide a cognitive framework for mapping the narrative world and comparing it with the real world.

Principally, the cognitive frames are associated with the reader's expectation, memory, experience, interaction and prediction. All these are activated, forming an efficient cognitive mechanism as the reader becomes involved in the interpretation of the story. In interpreting, the reader mostly focuses on the characters who play essential role in the story. Even with a brief character description, the readers consciously or unconsciously accumulate information in order to generate some expectations about the characters and story because the readers know that characters' actions are resulted from their beliefs and desires and also they know that the characters' mind functions "in ways that are similar to their own" (Palmer 2007: 207). Therefore, the readers transfer their knowledge about the characters' mentalities, physical features and behaviours as reference to their memory structure called 'script' that is a specific knowledge of a logical linearity of events or actions/functions. A scenario mainly concerns with a set of events or actions/functions. The reader also applies another type of cognitive frame called 'schema', through which he brings his prior experiences and expectations into the process of signification. The schema is a cognitive network of the real world multidimensional information sometimes called as 'encyclopedia knowledge' that organizes or structures the information into a logical and chronological linearity and makes the interaction or communication effective between the sender and receiver. Script and schemata are thus based on the real world experiences that are stored as cognitive frames that allow the interpreter to rapidly organize relevant information from different sources in a coherent, usable and predictive way.

In the literary signification, the cognitive frames primarily highlight the similar features of the fictional world and actual world by a process of creative comparison. The similarities are mostly revealed in the behaviors and traits of the characters, events and plot structure of the story. As the narrative is the result of a logical accumulation of these narrative elements, the reader needs to focus on the "events (actions), actors (those who are acted upon), and outcomes (results of the acts)" (Goodwin 1991: 103). The cognitive frames allow the reader not only to concentrate on those events or actions that play paramount role in the signification of story but also to ignore unnecessary information, unimportant actions of the characters and ineffective events of the story.

Another characteristic feature of the cognitive faculty is that it constantly compares and contrasts the newly developed experiences with the previous ones in order to develop new cognitive frames. However, the human being always consciously and unconsciously constructs meanings or continuously forms concepts from his environment. One of the ways of making a meaningful connection between new and old experiences is through metaphors that the reader always finds in the literary text. According to Pollio et al, "our conceptual systems are largely metaphoric in nature and that it is difficult to conceptualize any domain without using some figurative prototype" (Pollio et al 1990: 144).

The figurative elements are those through which the reader makes a connection between the literary discourse as new experience and real world as old experience. Basically, 
the interpretation of figurative expressions involves a kind of movement from known to unknown. Therefore, by applying these expressions, the author attempts to create an abstraction or complexity in the text so that the reader has to bring in an encyclopedia knowledge for their interpretation. As a result, through the figurative expressions that are integral parts and distinctive features of literary texts, the reader connects the literary text to the real life by his cognitive activities that enable the reader to aesthetically evaluate the expression in the literary narrative.

\section{Cognitive Frames as Cultural Mediation}

The interpreter's cognition is a main factor in the signification process of the literary text. It actually plays a mediating role between the text and a given culture or society, consequently contributing to the interpretation of the cultural ingredients of the text. Therefore, the first task of the reader is to determine the similar patterns between the story world and the real world These patterns mostly include "categorizations, thematic developments, structures of action and narration, characters, references to factual locations and events encountered in reading are from life. They may even exist in more precise and exemplary forms in literature and thus have more cognitive value. In interpreting these patterns, we [the readers] use experience acquired in everyday existence. Literary texts, considered as signs in this sense, are deeply embedded and conditioned by culture and society, yet are able to lead the reader to conceive new fictional worlds or discover new aspects in the factual world" (Veivo 2007: 47).

The literary discourse, as a manifestation of a given culture, is indeed composed of cultural codes along with their sub-codes serving as smallest cultural semantic units. The cultural codes of the discourse are actually those elements that help the reader to interpret the text. When a reader goes through reading the whole story, these codes motivate the reader to relate them to the relevant cognitive frames. Generally, the human being has a countless number of cognitive frames at his disposal; he activates those frames that correspond more to a given literary discourse.

The process of signification thus depends on not only the readers' cognitive activities, but also the textual structure, the cultural and social conventions and habits. All these factors must be taken into account for interpreting the structures of signification involving in any literary text. Hence, the understanding of the significance of a literary text cannot be achieved only through the habitual cognitive activities; rather it is a creative and imaginative process that takes into account various structural and cultural aspects of the text.

\section{Creativity of Cognition in Signification}

The cognitive faculty as a source of cultural information brings the relevant semantic content for not only any component of the story such as the characters' actions, events, textual symbols and figurative elements but also for any isolated or contextualized verbal expression. For instance, a word can be considered semantically in two ways: The one is that it can stand alone as an isolated item and can have a particular meaning. The second is that it can be applied in a specific context and its semantic content is determined only by its position in a given context. In fact, in absolute isolation, "no sign has any meaning; any sign-meaning arises in a context" (Hjelmslev 1953 [1943]: 28). Therefore, all the textual elements including figurative ones acquire their meaning only within the context of a given literary discourse.

Sometimes it happens that a person faces a new condition in which he does not know how to act since his cognition does not contain a relevant script for the new situation. In fact, he does not know which actions should be taken and in which order. In this condition, the cognition captures "the essence of concepts or stereotypical situations. This includes information about how to use the frame, information about expectations (which may turn out to be wrong), information about what to do if expectations are not confirmed, and so on (Nebel 1999: 324). However, the cognitive activity is not limited to only the fixed scripts or any specific cognitive frame. It is a creative phenomenon that always creates new programs or scripts for the new conditions. Similarly, the reader may encounter an unknown and unexpected literary discourse that does not match with his cognitive frames. In this case, the cognition starts making new cognitive scripts corresponding to the literary discourse under consideration. Another problem for the reader is that the story world never represents all the aspects of the real world because the literary discourse is not long enough to represent the story with all its details. Sometimes, some of the actions or characters may not be there in the story. Hence the cognitive faculty, as a mediator between the text and the real world, provides the reader with the relevant source to trace the absent aspects of the story.

\section{Conclusions}

The semiotic analysis of a literary text deals with the way in which meaning is produced by the syntactical structure of interdependent textual signs that are organized under the syntagmatic and paradigmatic forces of the discourse or discursive conventions. It implies that the process of literary signification constitutes three factors: Syntactical structure, semantic constituents and pragmatic aspects of the text. Here, we intend to discuss in detail these factors: Syntactical, Semantic and Pragmatic dimension of literary text. The syntactical structure is the primary operation for the foundation of any kind of sign system. In accordance with the Saussure's semiological model which emphasizes on the structural aspects of sign systems, the task of the 
semioticians is to consider the systematic characteristics of the sign system. The primary goal is to find out the underlying conventions, rules or techniques by which the signs are interrelated and create a logical and coherent system. On the other hand, Peirce has defined the sign in the terms of his triadic model emphasizing on the relationship of the 'sign' with other two factors; 'object' and 'interpretant'. The same view should be taken on the linguistic signs. In fact, a linguistic sign "represents and refers to a universe of discourse by means of linguistic rules, cognitive models and discursive conventions. Thus, one basic dimension of a text consists in the triadic relationship between sign, object, and what is by Peirce called the interpretant of the sign (i.e., the rules, models, and conventions that make the text understandable)" (Johansen 2007a: 108-9). If Peirce's triadic model is taken as a framework for the analysis of literary text, the textual elements can be considered as signs, its function as object and its argument as interpretant. Therefore, the literary text as a sign system is constructed by its elements that are organized in a logical linearity by the discursive conventions. So the first step in the interpretation of any literary text, i.e. a narrative, is to deconstruct the text into its elements such as settings, events and plot structures, and to find out the characters' traits, narrator, formal aspects of the text and the literary styles or techniques that have been applied for the organization of narrative. In fact, it depends on the reader's sense of the overall organization and patterning of the narrative and the way in which the textual elements fit together to produce a coherent discourse.

The literary text is composed of a sequence of minimal semantic units. A combination of two or several units forms a motif, and a combination of two or several motifs forms a theme and a combination of themes forms a narrative discourse. Then a literary text is a configuration of themes. So, semiotic analysis of narrative concerns also with the 'thematic configuration' of narrative. The intention is to delineate the thematic patterns inherent in the literary discourse.

The pragmatic aspects of the literary text deal with the cultural aspects that are manifested or represented through its narrative units, carrying cultural semantic contents. These units indeed serve as socio-symbolic mediations that relate the literary text to a given culture. These textual elements can be thus interpreted by taking into consideration the cultural aspects of a given society. Hence, semiotic analysis deals with the 'figurative dimensions' of novel and the intention here is mainly to decode the figurative elements such as metaphor, metonymy, hyperbole, parody, irony and other symbolic components of the literary discourse.

\section{REFERENCES}

[1] Barthes, Roland (1964). Elements of Semiology. Trans. Annette Lavers \& Colin Smith. London: Jonathan Cape.
[2] Barthes, Roland (1966a). "Introduction to the Structural Analysis of Narrative." In: Barthes, R. (1977). Image-Music-Text. New York: Hill \& Wang. pp.79-124.

[3] Barthes, Roland (1974). S/Z. Trans. R. Miller. New York: Hill and Wang.

[4] Bertens, Hans (2001). Literary Theory. London: Routledge.

[5] Bonheim, Helmut (2000). "Shakespeare's Narremes." In: Holland, Peter (Ed.). Shakespeare Survey 53: Shakespeare and Narrative. Cambridge: Cambridge University Press. pp. $1-11$.

[6] Bremond, Claude (1966). "The Logic of Possible Narrative." Communications, volume 8, Paris, Editions du Senil. pp. 60-76.

[7] Chandler, Daniel (2007). Semiotics: The Basics. Second Edition. London: Routledge.

[8] Chatman, Seymour (1978). Story and Discourse: Narrative Structure in Fiction and Film. London: Cornell University Press.

[9] Dolezel, Lubomir (1972). "From Motifemes to Motifs." Poetics, volume 4, pp. 55-90.

[10] Dorothy, Hale J. (2006). The Novel: An Anthology of Criticism and Theory 1900-2000. Oxford: Blackwell.

[11] Eco, Umberto (1976). A Theory of Semiotics. Bloomington, IN: Indiana University Press/London: Macmillan.

[12] Fisette, Jean (2007). "Literary Practice on the Immediate Horizon of the Elaboration of Semiotic: Peirce's Meeting with a Few Great Authors." Semiotica, volume 165-1/4, pp. 67-89.

[13] Genette, Gerard ([1972] 1983). Narrative Discourse. Oxford: Oxford University Press.

[14] Gerrig, Richard J. and David W. Allbritton (1990). "The Construction of Literary Character: A View from Cognitive Psychology." Style, volume 24, pp. 380-91.

[15] Gonzalez-Marquez, Monica (2006). Methods in Cognitive Linguistics. Philadelphia: J. Benjamins Publication.

[16] Goodwin, David (1991). "Employing the Reader: Motivation and Technical Documentation." Technical Writing and Communication, volume 21, pp. 99-115.

[17] Greimas, Algirdas J. (1987). On Meaning: Selected Writings in Semiotic Theory. Trans. Paul J. Perron \& Frank H. Collins. London: Frances Pinter.

[18] Greimas, Algirdas J. ([1966] 1983): Structural Semantics. Lincoln, NB: University of Nebraska Press.

[19] Guiraud, Pierre (1975). Semiology. Trans. George Gross. London: Routledge \& Kegan Paul.

[20] Hawkes, Terence (1977). Structuralism and Semiotics. London: Routledge.

[21] Hjelmslev, Louis (1953 [1943]). Prolegomena to a Theory of Language. Baltimore: Waverly Press.

[22] Johansen, Jorgen D. (2007b). "Preface." Semiotica, volume 165-1/4, pp. 1-10.

[23] Johansen, Jorgen D. (1986). "The Place of Semiotics in the Study of Literature." In: Evans, Jonathan D., and Andre 
Helbo (Ed.). Semiotics and International Scholarship. Dordrecht: Nijhoff. pp. 101-126.

[24] Johansen, Jorgen D. (2007a). "A Semiotic Definition of Literary Discourse." Semiotica, volume 165-1/4, pp. 107-132.

[25] Kristeva, Julia (1984). Revolution in Poetic Language. Trans. M. Waller. New York: Columbia University Press.

[26] Labov, William (1972). Language in the Inner City. Philadelphia: University of Pennsylvania Press.

[27] Langendonck, William (2007). "Iconicity.” In: Geerraerts, Dirck and Hubert Cuyckens (Ed.). The Oxford Handbook of Cognitive Linguistics. New York: Oxford University Press. pp. 394-418.

[28] Lothe, Jakob (2000). Narrative in Fiction and Film: An Introduction. New York: Oxford University Press Inc.

[29] Lotman, Jurij et al. (1975). Theses on the Semiotic Study of Culture. Lisse: de Ridder Press.

[30] Ludovic, De Cuypere (2008). Limiting the Iconic: From the Metatheoretical Foundations to the Creative Possibilities of Iconicity in Language. Amsterdam: John Benjamins.

[31] Martin, B. and F. Ringham (2006). Key Terms in Semiotics. London: Bookens Ltd.

[32] Morris, Charles W. (1938/1970). Foundations of the Theory of Signs. Chicago: Chicago University Press.

[33] Nebel, Bernhard (1999). "Frame-based Systems." In: Robert, Wilson A. and Frank C. Keil (Ed.). MIT Encyclopedia of the Cognitive Science. Cambridge, MA: MIT Press. pp. 324-326.

[34] Noth, Winfried (1990). Handbook of Semiotics. Bloomington: Indiana University Press.

[35] Palmer, Alan (2007). "Universal Mind." Semiotica, volume $165-1 / 4$, pp. 205-225.

[36] Pavel, Thomas G. (1985). "Literary Narrative.” In: Van Dijk, Teun A. (Ed.). Discourse and Literature. Amsterdam: Benjamins Publishing Co. pp. 85-103.

[37] Peirce, Charles S. (1907). The Essential Peirce. Selected Philosophical Writings. vol. 1 (1867-1893), edited by Nathan Houser \& Christian Kloesel, 1992, vol. 2 (1893-1913), edited by the Peirce Edition Project, 1998. Bloomington and Indianapolis: Indiana University Press.

[38] Peirce, Charles S. (1931). Collected Papers of Charles Sanders Peirce, 8 volumes, vols. 1-6, eds. Charles Hartshorne and Paul Weiss, vols. 7-8. Ed. Arthur W. Burks. Cambridge, Mass.: Harvard University Press.

[39] Pollio, Howard R., Smith Michael K. and Marilyn R. (1990). "Figurative Language and Cognitive Psychology." Language and Cognitive Processes, volume 5, no. 2, pp. 141-167.

[40] Posner, Roland (1992). "Origin and Development of Contemporary Syntactics." Languages of Design: Formations for Word, Image and Sound. Vol. 1, no. 1, September, pp.33-50.

[41] Propp, Vladimir (1928). Morphology of the Folktale. Second Edition. Trans. Laurence Scott. Austin: University of Texas Press.

[42] Ricoeur, Paul (2002). Time and Narrative. Chicago [u.a.]: University of Chicago Press.

[43] Rimmon-Kenan, S. (2002). Narrative fiction: Contemporary Poetics. London: Methuen \& Co. Ltd.

[44] Rizzoli, Renato (1999). Representation and Ideology in Jacobean Drama: The Politics of the Coup De Theatre. New York: The Edwin Mellen Press.

[45] Ryan, Marie-Laure (1985). "Model Structure of Narrative Universe." Poetics Today, volume 6, pp. 717-755.

[46] Santaella, Lucia (2007). "The contribution of Peirce's Philosophical Disciplines to Literary Studies." Semiotica, volume $165-1 / 4$, pp. 57-66.

[47] Tejera, Victorino (1995). Literature, Criticism, and the Theory of Signs. AmeFFsterdam: John Benjamins Publishing Co.

[48] Todorov, Tzvetan (1965). Theories of Literature: Text and Russian Formalism. Paris: Seuil.

[49] Todorov, Tzvetan (1969). Grammar in Decameron. Mouton: The Hague.

[50] Trotsky, Leon (1957). Literature and Revolution. New York: Russell.

[51] Van Dijk, Teun A. (1976). "Narrative Macro-structures: Logical and Cognitive Foundations." PTL: Journal for Descriptive Poetics and Theory of Literature, volume 1, pp. 547-68.

[52] Van Dijk, Teun A. (1985). Discourse and Literature. Amsterdam: Benjamins Publishing Co.

[53] Waugh, Patricia (2006). Literary Theory and Criticism. Oxford [u.a.]: Oxford University Press. 